\title{
Afyon Manda Kaymağı ve Kaymakaltı Sütlerinde Bazı Ağır Metallerin ICP-MS ile Araştırılmasi ${ }^{\#}$
}

\author{
Fahriye KAN*', İsmail KÜÇÜKKURT ${ }^{1}$ \\ ${ }^{1}$ Afyon Kocatepe Üniversitesi, Veteriner Fakültesi, Biyokimya Anabilim Dall, Afyonkarahisar
}

\#Bilimsel Arastirma Projeleri Komisyonu 13. SAĞ. BİL. 19 proje numarasyla desteklenmis, yükesek lisans tęinden (AKÜ Sağllk. Bilimleri Enstitüsï, 2015-007) derive edilmiş ve 7. Ulusal Veteriner Biyokimya ve Klinik. Biyokimya Kongresinde poster olarak sunulmustur.

*Corresponding author e-mail: fahriyekan@gmail.com

\section{ÖZ}

Endüstri gelişimine bağlı ortaya çıkan ve artarak devam eden ağır metal kirliliğinin süt ve süt ürünlerine bulaşması doğrudan ve dolaylı yollardan olabilmektedir. Bu çalışma, Afyonkarahisar ilinin bazı bölgelerinden toplanan manda sütlerinin kaynatılması ile elde edilen kaymak ve kaymakaltı sütlerinde olası ağır metal varlığının ICP-MS cihazı ile araştırılması amaçlanmıştır. Afyonkarahisar ilinin beş farklı bölgesinden toplanan elli adet süt örneği 200 ml'lik cam kavanozlara alındı. Süt numunelerinin laboratuar ortamında beherler içinde kaynatılması ile kaymak ve kaymakaltı sütleri elde edildi. Yaş yakma yöntemiyle numuneler çözünürleştirildikten sonra ağır metal miktarları ICP-MS cihazıyla tayin edildi ve sonuçlar literatür bilgileriyle karşılaştırılarak değerlendirildi. Araştırmada kaymaktaki ortalama krom (Cr), mangan (Mn), demir (Fe), kobalt (Co), nikel (Ni), bakır (Cu), çinko (Zn), arsenik (As), selenyum (Se), molibden (Mo), gümüş (Ag), kadmiyum (Cd), baryum (Ba) ve kuşun $(\mathrm{Pb})$ değerleri sırasıyla: $0,36 \mathrm{mg} / \mathrm{kg}, 0,56 \mathrm{mg} / \mathrm{kg}, 2,72 \mathrm{mg} / \mathrm{kg}, 0,08 \mathrm{mg} / \mathrm{kg}, 0,65 \mathrm{mg} / \mathrm{kg}, 0,09 \mathrm{mg} / \mathrm{kg}, 8,27$ $\mathrm{mg} / \mathrm{kg}, 0,14 \mathrm{mg} / \mathrm{kg}, 0,94 \mathrm{mg} / \mathrm{kg}, 0,00 \mathrm{mg} / \mathrm{kg}, 0,00 \mathrm{mg} / \mathrm{kg}, 0,00 \mathrm{mg} / \mathrm{kg}, 0,17 \mathrm{mg} / \mathrm{kg}, 0,01 \mathrm{mg} / \mathrm{kg}$; kaymak altı sütünde ise $0,02 \mathrm{mg} / \mathrm{L}, 0,13 \mathrm{mg} / \mathrm{L}, 0,52 \mathrm{mg} / \mathrm{L}, 0,02 \mathrm{mg} / \mathrm{L}, 0,12 \mathrm{mg} / \mathrm{L}, 0,02 \mathrm{mg} / \mathrm{L}, 2,37 \mathrm{mg} / \mathrm{L}, 0,04 \mathrm{mg} / \mathrm{L}, 0,17 \mathrm{mg} / \mathrm{L}, 0,04 \mathrm{mg} / \mathrm{L}$, $0,00 \mathrm{mg} / \mathrm{L}, 0,00 \mathrm{mg} / \mathrm{L}, 0,13 \mathrm{mg} / \mathrm{L}, 0,01 \mathrm{mg} / \mathrm{L}$ düzeylerinde tespit edildi. Sonuç olarak manda sütlerinden elde edilen kaymak ve kaymakaltı sütlerinde insan sağlığı açısından zararlı olabilecek bir ağır metal kontaminasyonun bulunmadığı görüldü. Bu çalışma ağır metallerin kaymakaltı sütünden ziyade kaymakta görülmesi nedeniyle kaymak yapımında kullanılan sütlerin ağır metal yönünden risk oluşturmaması için sütlerin kontaminasyonlarının önlenmesinin önemini göstermektedir. Anahtar Kelimeler: Afyonkarahisar, Afyon Manda Kaymağı, Ağır Metal, ICP-MS, Kaymakaltı Sütü.

\section{Investigation of Some Heavy Metals with ICP - MS in Afyon Buffalo Kaymak and Skimmed Milk}

\begin{abstract}
According to industrial development heavy metal pollution affects milk and milk products directly and indirectly. It was aimed to evaluate occurrence of heavy metal in kaymak and skimmed milk, produced from boiled Anatolian buffalo milk and obtained from Afyonkarahisar, measurement performed by means of ICP-MS. Totally 50 milk samples were collected from 5 different regions of Afyonkarahisar. To get kaymak and skimmed milk, samples were boiled in beakers under laboratory circumstances. Samples were dissolved according to wet digestion method afterwards quantity of heavy metals were determined by ICP-MS and obtained results were compared with literature values. In the study, average values of chromium (Cr), manganese $(\mathrm{Mn})$, iron $(\mathrm{Fe})$, cobalt $(\mathrm{Co})$, nickel $(\mathrm{Ni})$, copper $(\mathrm{Cu})$, zinc $(\mathrm{Zn})$, arsenic (As), selenium (Se), molybdenum (Mo), silver (Ag), cadmium $(\mathrm{Cd})$, barium $(\mathrm{Ba})$ and lead $(\mathrm{Pb})$ were determined in clotted cream: $0,36 \mathrm{mg} / \mathrm{kg}$, $0,56 \mathrm{mg} / \mathrm{kg}, 2,72 \mathrm{mg} / \mathrm{kg}, 0,08 \mathrm{mg} / \mathrm{kg}, 0,65 \mathrm{mg} / \mathrm{kg}, 0,09 \mathrm{mg} / \mathrm{kg}, 8,27 \mathrm{mg} / \mathrm{kg}, 0,14 \mathrm{mg} / \mathrm{kg}, 0,94 \mathrm{mg} / \mathrm{kg}, 0,00 \mathrm{mg} / \mathrm{kg}, 0,00$ $\mathrm{mg} / \mathrm{kg}, 0,00 \mathrm{mg} / \mathrm{kg}, 0,17 \mathrm{mg} / \mathrm{kg}, 0,01 \mathrm{mg} / \mathrm{kg}$; in skimmed milk: $0,02 \mathrm{mg} / \mathrm{L}, 0,13 \mathrm{mg} / \mathrm{L}, 0,52 \mathrm{mg} / \mathrm{L}, 0,02 \mathrm{mg} / \mathrm{L}, 0,12$ $\mathrm{mg} / \mathrm{L}, 0,02 \mathrm{mg} / \mathrm{L}, 2,37 \mathrm{mg} / \mathrm{L}, 0,04 \mathrm{mg} / \mathrm{L}, 0,17 \mathrm{mg} / \mathrm{L}, 0,04 \mathrm{mg} / \mathrm{L}, 0,00 \mathrm{mg} / \mathrm{L}, 0,00 \mathrm{mg} / \mathrm{L}, 0,13 \mathrm{mg} / \mathrm{L}, 0,01 \mathrm{mg} / \mathrm{L}$ respectively. Kaymak and skimmed milk obtained from Anatolian buffaloes milk did not have heavy metal contamination that may be harmful to human health. This study shows the importance of preventing heavy metal contamination of milk used for making kaymak because this contamination is important in kaymak than skimmed milk
\end{abstract}

Keywords: Afyonkarahisar, Anatolian buffalo kaymak, heavy metals, ICP-MS, skimmed milk. 


\section{GİRIŞ}

Kaymak, Türkiye'ye has geleneksel bir ürün olup en iyi kaymak yă̆ oranı yüksek, kuru madde bakımından zengin ve kaymak bağlama yeteneğinin yüksek olması sebebiyle manda sütünden yapilmaktadır. Kaymak; kadayıf, baklava gibi tatlılar üzerine konulup süsleme ve tat verme amaciyla yenilmesi yanında kahvaltılarda da tüketilmek üzere değişik şekilde ve ambalajlar içerisinde sunulan bir üründür (Akalın ve ark., 2006).

Çeşitli süt ürünlerinin üretiminde önemli bir kalite kriteri olan süt yağı Türkiye'de bazı yöresel süt ürünlerinin üretiminde kaymak yapımında kullanılır. Özellikle Afyon, Edirne, Kocaeli, İstanbul, Bursa, Ankara illerinde genellikle küçük aile işletmelerinde üretilir ve "Lüle Kaymağı" olarak satıllır (Kurt ve Özdemir, 1988 ; Çon ve ark., 2000). Ayrıca kaymak Afyon yöresinde lokumun içerisine sarlarak kaymaklı lokum şeklinde tüketilmektedir (Adam, 1971). Kaymak üretiminde çeşitli hayvan sütleri kullanılmakla birlikte daha çok manda sütü tercih edilir. Manda sütünün yağ ve kuru madde miktarının yüksek olması ve yağ renginin de beyaz olması kaymak üretiminde tercih edilmesinin başlıca nedenidir (Tekinşen, 2000).

Atmosferdeki değişik gaz ve parçacıkların fazlalığı, fabrika bacalarından çıkan hava kirleticiler ve atıkları toprak ve bitki verimliliğine olumsuz etkide bulunmakta ve bitkilerle beslenen insan ve hayvanları olumsuz yönde etkileyebilmektedir. Özellikle yirminci yüzyılın ikinci yarısında endüstri gelişimine bağlı olarak ortaya çıkan ve artarak devam eden hava ve ağır metal kirliliği artmış olup günümüzde bütün canlılar üzerinde tehdit oluşturmaktadır (Zheljazkov ve Nielsen, 1996). Ağır metal grubuna kurşun (Pb), kadmiyum (Cd), demir $(\mathrm{Fe})$, kobalt $(\mathrm{Co})$, bakır $(\mathrm{Cu})$, nikel $(\mathrm{Ni})$, civa $(\mathrm{Hg})$ ve çinko $(\mathrm{Zn})$ başta olmak üzere 60'tan fazla metal dahildir (Kahvecioğlu ve ark., 2003). Zehirleyici özelliğe sahip ağır metaller çeşitli kaynaklardan çevreye yayılmakta ve günümüzde çevre kirliliğinin önemli nedenlerinden birini oluşturmaktadır (Goyer, 1991). Su, toprak ve havanın kirlenmesiyle birlikte ekolojik dengenin bozulması sonucu gida maddelerine geçen ağır metaller insan sağllğını tehdit etmekte ve bu gelecek kuşaklara da geçebilmektedir. Ağır metallerin süt ve süt ürünlerine bulaşması; süt ürünlerinin sağıldığ1 kaplar, süt taşımada kullanılan tanklar, süt ürünlerinin hazırlandığı ortamlar gibi doğrudan olabilir. Ya da farklı kaynaklardan çevreye bulaşan atıkların ağır metal içeriklerinin hayvanın tükettiği yeme ulaşması, hayvanın içtiği su, soluduğu hava gibi dolaylı yollardan da olabilir.
Yapılan bu çalışma ile Afyonkarahisar'da bulunan baz1 bölgelerden toplanan manda sütünün kaynatilması ile elde edilen kaymak ve kaymakaltı sütlerinde ağır metal varlığının ICP-MS cihazı ile araştırılması amaçlanmıştır.

\section{MATERYAL- METOT}

\section{Örneklerin alınması}

Manda sütleri, Afyonkarahisar il ve ilçelerinden 5 farklı bölgeden toplam 50 adet cam kavanozlara $200 \mathrm{ml}$ olarak toplandı. Süt örneklerinin alındığı ve kaymak üretimi yapilan malzemeler 1:1 $\mathrm{HNO}_{3}$ çözeltisinde 12 saat bekletildikten sonra ultra distile su (ELGA DV 25) ile yıkandı ve kurutuldu.

\section{Kaymak Üretimi}

Sütler toplandıktan sonra bekletilmeden beherlerde bek üzerinde yaklaşı $30 \mathrm{dk}$ süre ile $95^{\circ} \mathrm{C}^{\prime}$ ye gelinceye kadar isitıldı. Isıtma işlemi sonrası beherler oda sicakllğında 1-2 saat soğumaya birakilarak ardindan $+4{ }^{\circ} \mathrm{C}$ 'de $12-14$ saat bekletildi. Süre sonunda oluşan kaymak tabakası yine cam kavanozlara alındı.

\section{Örneklerin Hazırlanması}

Kaymak ve kaymakaltı sütü örneklerinin çözümleme işlemleri için kapalı sistem mikrodalga yakma metodu kullanıldı. Sineo MDS- 10 marka mikrodalga kapalı sistemde HP-100 teflon kaplar kullanıldı. Kaymakaltı sütü örneği için; her bir teflona önce mikropipet yardımıyla süt örneğinden $2 \mathrm{ml}$ alındı ve üzerine $8 \mathrm{ml} \%$ 65'lik $\mathrm{HNO}_{3}$ eklendi üzerine $1 \mathrm{ml} \% 30$ 'luk $\mathrm{H}_{2} \mathrm{O}_{2}$ eklendikten sonra 15$20 \mathrm{dk}$ bekletildi. Teflon kapların kapakları sıkıştırılarak çözündürme işlemi için $130{ }^{\circ} \mathrm{C}$ 'de 10 $\mathrm{dk}, 150{ }^{\circ} \mathrm{C} 5 \mathrm{dk}$ ve $180{ }^{\circ} \mathrm{C}$ 'de $10 \mathrm{dk}$ şeklinde yaş yakma cihazında yakma işlemi uygulandı. Kaymak örneği için; önce 0,5 g kaymak hassas terazide tartılarak teflon kaplara alındı ve üzerine $6 \mathrm{ml}$ $\mathrm{HNO}_{3}$ eklendi. 15 dakika ön muameleden sonra 3 $\mathrm{ml} \mathrm{HNO}_{3}$ ve üzerine $1 \mathrm{ml} \mathrm{H}_{2} \mathrm{O}_{2}$ eklendi. Çözünürleştirme için yaş yakma cihazında 130 ${ }^{\circ} C^{\prime}$ de $10 \mathrm{dk}, 150{ }^{\circ} \mathrm{C}^{\prime} \mathrm{de} 5 \mathrm{dk}, 180{ }^{\circ} \mathrm{C}^{\prime} \mathrm{de} 15 \mathrm{dk}$ şeklinde sicaklık dereceleri ayarlanarak yaş yakma yöntemi uygulandi.

\section{ICP - MS ile Ölçüm}

Çözünürleştirme işlemi sonrası oda sıcaklı̆̆ında soğutulan kapların kapakları açıldıktan sonra teflondan çözünmüş çözeltiler $50 \mathrm{ml}$ 'lik balon jojelere alındı. Çözeltiye $50 \mathrm{ml}$ ultra distile su eklenerek seyreltme işlemi gerçekleştirildi ve örnekler plastik tüplere alındı. Daha sonra örnekler 25/0,45 $\mu$ m'lik filtrelerden (econofilter) süzüldü ve okuma işlemine kadar buzdolabında $+4{ }^{\circ} \mathrm{C}$ 'de bekletildi. Metal kontaminasyonunu önlemek amacıyla örneklerin çözündürülmesi esnasında 
kullanilan tüm malzemeler, $\mathrm{HNO}_{3}(1: 1)$ ve ultra distile su (1/9)'dan geçirildi. Ağır metal analizlerinin gerçekleştirilmesi için Agilent 7700 seri ICP-MS cihazı kullanıldı.

\section{BULGULAR}

Toplanan sütlerden elde edilen kaymak ve kaymakaltı sütlerinin minimum, maksimum, ortalama ve standart sapma değerleri Tablo 1'de verilmiştir. Buna göre $\mathrm{Ag}$ ve $\mathrm{Cd}$ kaymakta ve kaymakaltı sütünde tespit edilebilir değerin altında bulundu. Manda sütünden elde edilen kaymakların hiçbirisinde Mo ağır metali tespit edilmedi fakat kaymakaltı sütünde Mo varlığ1 tespit edilmiştir. Cr, $\mathrm{Mn}, \mathrm{Fe}, \mathrm{Co}, \mathrm{Ni}, \mathrm{Cu}, \mathrm{Zn}$, As, Se, Cd, ve Ba kaymaktaki ortalama değerleri kaymak altı sütüne göre daha fazla olduğu tespit edildi. Pb kaymakta ve kaymak altı sütünde ortalama değerleri aynı iken standart sapma ve maksimum değeri kaymak altı sütünde daha yüksek olduğu görüldü.

\section{TARTIŞMA ve SONUÇ}

Araştırmada elde edilen bulgular incelendiğinde $\mathrm{Cr}$ değerlerinin kaymakta $0,36 \mathrm{mg} / \mathrm{kg}$ ve kaymakaltı sütünde $0,02 \mathrm{mg} / \mathrm{L}$ olarak tespit edildi. Soylu ve Temiz (2011) Samsun bölgesinde yaptikları çalışmada sığır süt örneklerinde Cr'u $0,03 \mathrm{mg} / \mathrm{kg}$ olarak bulmuşlardır. Öksüztepe ve ark. (2013), 25 çökelek ve 25 kurut olmak üzere toplam 50 numuneden oluşan çalışmalarında $\mathrm{Cr}$ seviyelerini çökelekte $0,06 \mathrm{mg} / \mathrm{kg}$ ve kurut örneklerinde 0,09 $\mathrm{mg} / \mathrm{kg}$ olarak saptamışlardır. Her iki çalışmadaki Cr miktarları yapılan çalışmada elde ettiğimiz kaymaktaki değerden düşük; kaymakaltı sütü örneklerinin değerlerinden yüksek olduğu görüldü. Aslam ve ark. (2011), Pakistan'da yaptıkları çalışmada keçi ve sığır sütlerindeki ağır metal varlığını mevsimsel olarak incelemişler ve toplamda hayvanların sütlerinde $\mathrm{Cr}$ miktarlarını keçilerde 1,277 mg/L, sığırlarda 1,199 mg/L olarak yüksek seviyelerde bulmuşlardır. Bunun sebebinin toprak yapıs1, otlakların sanayi bölgelerine yakın olması ve sütün elde edilmesi sirasinda meydana gelen kontaminasyonlardan olabileceğini belirtmişlerdir. Aynı yönde Temurci ve Güner (2006), sütte Cr ortalama değerini $1,02 \mathrm{mg} / \mathrm{kg}$ ve peynirde 2,60 $\mathrm{mg} / \mathrm{kg}$ olarak bulmuşlardır. Süt ve peynirdeki yüksek değerlerdeki Cr'un süt ve peynir üretiminin muhafazasinda kullanilan kaplardan kaynaklanabileceğini düşünmüşlerdir. Afyonkarahisar'da manda kaymak ve kaymakaltı sütlerinde önemli bir $\mathrm{Cr}$ kirliliğinin olmadığ 1 söylenebilir.

Kaymakta Mn 0,56 mg/kg, kaymakaltı sütünde $0,13 \mathrm{mg} / \mathrm{L}$ olarak tespit edildi. Samsun'da sanayi emisyonlarının yöre sığır sütlerinin ağır metal içeriğine etkisinin araştırıldığ1 çalışmada Mn’ın ortalama miktarı $0,048 \mathrm{mg} / \mathrm{kg}$ olarak bildirilmiştir. Enb ve ark. (2009), manda ve inek sütü ile yaptıkları çalışmada manda sütlerinde Mn miktarını $0,076 \mathrm{mg} / \mathrm{kg}$ inek sütlerindeki $\mathrm{Mn}$ miktarını ise 0,056 $\mathrm{mg} / \mathrm{kg}$ olarak tespit etmişlerdir. Aynı çalışmada çeşitli süt ürünlerinden kaymak, tereyağ gibi süt ürünlerinde Mn miktarları en yüksek tereyağında $0,316 \mathrm{mg} / \mathrm{kg}$, kremada ise $0,234 \mathrm{mg} / \mathrm{kg}$ olarak tespit etmişlerdir. Bu çalışmamızdaki bulgular dikkate alındığında kaymakta tespit edilen Mn değerlerinin bu çalışmalardan yüksek olduğu görülmektedir. Öksüztepe ve ark. (2013), yaptıklar1 çalışmada ise Elazı̆̆'da tüketime sunulan çökelek ve kurut örneklerinde çökelekte $0,41 \mathrm{mg} / \mathrm{kg}$ kurutta 1,25 $\mathrm{mg} / \mathrm{kg}$ düzeyinde $\mathrm{Mn}$ olduğunu tespit etmişlerdir. Bu çalışmada bulunan değerler yapılan çalışma ile uyumlu görülmektedir.

Elde edilen bulgular $\mathrm{Fe}$ yönünden incelendiğinde kaymakta $2,72 \mathrm{mg} / \mathrm{kg}$ ve kaymakaltı sütünde 0,52 $\mathrm{mg} / \mathrm{L}$ olarak tespit edildi. Temurci ve Güner (2006)'in Ankara'da süt ve beyaz peynirlerde ağır metal kontaminasyonu üzerine yaptıkları çalışmada sütte ortalama Fe değerini $52,19 \mathrm{mg} / \mathrm{L}$ ve peynir numunelerinde $62,56 \mathrm{mg} / \mathrm{kg}$ olarak bulmuşlardır. Yalçın ve Tekinşen (2010) beyaz salamura, tulum ve kaşar peynirlerinin Fe içeriklerini sırasıyla 17,47 $\mathrm{mg} / \mathrm{kg}, \quad 14,18 \mathrm{mg} / \mathrm{kg}$ ve $15,42 \mathrm{mg} / \mathrm{kg}$ olarak saptamışlardır. $\mathrm{Bu}$ çalışmalardaki yüksek $\mathrm{Fe}$ değerlerinin topraktaki demir içeriğinden, ürünlerin metal kaplarda muhafaza edilmesinden ve elle yapılan sağımdan kaynaklanabileceğini söylemişlerdir. Özlü ve ark. (2012), taze ve olgunlaşmış kaşarlarda Fe değerlerini sırasıyla 1,71 $\mathrm{mg} / \mathrm{kg}$ ve $1,49 \mathrm{mg} / \mathrm{kg}$ olarak bulmuşlardır. Soylu ve Temiz (2011), sığır sütlerinde ortalama Fe miktarın $0,39 \mathrm{mg} / \mathrm{kg}$ olarak tespit etmişlerdir. Bu çalışmalar sütte ve süt ürünlerinde Fe değerlerinin farklı miktarlarda olabileceğini göstermekle birlikte yapılan çalışma ile uyumlu olarak sütten ziyade süt ürünlerinde Fe'in daha yüksek olduğunu göstermektedir.

Kaymakta Co $0,08 \mathrm{mg} / \mathrm{kg}$ ve kaymakaltı sütünde 0,02 mg/L olarak tespit edildi. K1liçel ve ark. (2004), otlu lorlarda Co içeriğini ortalama 0,29 $\mathrm{mg} / \mathrm{kg}$, Benincasa ve ark. (2008) ise manda sütünde Co ortalama değerini 2,10 $\mu \mathrm{g} / \mathrm{kg}$ ve inek sütünde $1,44 \mu \mathrm{g} / \mathrm{kg}$ olarak bulmuşlardır. Her iki çalışmadaki Co değerleri yapılan çalışmada elde edilen değerlerden yüksek bulunmuştur. Co değerlerinin yapılan çalışmada düşük olması insan sağlı̆̆1 açisından olumlu bulunmaktadır. 
Tablo 1. Toplam Kaymak ve Kaymakaltı Sütünde Ağır Metal Düzeyleri $(\mathrm{mg} / \mathrm{kg}, \mathrm{mg} / \mathrm{L})$

Table 1. Heavy Metal Levels in Total Kaymak and Scimmed Milk(mg / kg)

\begin{tabular}{llllllllllllllllllllllllllll}
\hline $\mathrm{Cr}$ & $\mathrm{Mn}$ & $\mathrm{Fe}$ & $\mathrm{Co}$ & $\mathrm{Ni}$ & $\mathrm{Cu}$ & $\mathrm{Zn}$ & $\mathrm{As}$ & $\mathrm{Se}$ & $\mathrm{Mo}$ & $\mathrm{Ag}$ & $\mathrm{Cd}$ & $\mathrm{Ba}$ & $\mathrm{Pb}$ \\
\hline
\end{tabular}

\begin{tabular}{|c|c|c|c|c|c|c|c|c|c|c|c|c|c|c|c|}
\hline \multirow{3}{*}{$\begin{array}{l}\text { है } \\
\text { है } \\
\text { है }\end{array}$} & $\mathrm{X} \pm \mathrm{Sx}$ & $0,36 \pm 0,48$ & $0,56 \pm 0,69$ & $2,72 \pm 3,57$ & $0,08 \pm 0,08$ & $0,65 \pm 0,66$ & $0,09 \pm 0,31$ & $8,27 \pm 12,70$ & $0,14 \pm 0,15$ & $0,94 \pm 1,18$ & $0,00 \pm 0,00$ & $0,00 \pm 0,00$ & $0,00 \pm 0,00$ & $0,17 \pm 0,10$ & $0,01 \pm 0,02$ \\
\hline & $\min$ & 0,00 & 0,00 & 0,00 & 0,00 & 0,00 & 0,00 & 0,59 & 0,00 & 0,00 & 0,00 & 0,00 & 0,00 & 0,00 & 0,00 \\
\hline & $\max$ & 1,23 & 2,27 & 9,29 & 0,23 & 1,77 & 1,79 & 81,51 & 0,51 & 2,77 & 0,00 & 0,00 & 0,02 & 0,40 & 0,12 \\
\hline \multirow{3}{*}{ 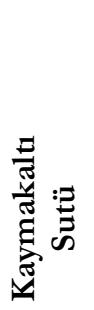 } & $\mathrm{X} \pm \mathrm{Sx}$ & $0,02 \pm 0,04$ & $0,13 \pm 0,17$ & $0,52 \pm 0,79$ & $0,02 \pm 0,03$ & $0,12 \pm 0,15$ & $0,02 \pm 0,11$ & $2,37 \pm 2,22$ & $0,04 \pm 0,05$ & $0,17 \pm 0,27$ & $0,04 \pm 0,08$ & $0,00 \pm 0,00$ & $0,00 \pm 0,00$ & $0,13 \pm 0,07$ & $0,01 \pm 0,03$ \\
\hline & $\min$ & 0,00 & 0,00 & 0,00 & 0,00 & 0,00 & 0,00 & 0,34 & 0,00 & 0,00 & 0,00 & 0,00 & 0,00 & 0,02 & 0,00 \\
\hline & $\max$ & 0,16 & 0,47 & 2,96 & 0,07 & 0,42 & 0,81 & 9,28 & 0,16 & 0,71 & 0,26 & 0,00 & 0,00 & 0,29 & 0,22 \\
\hline
\end{tabular}


Kaymakta Ni $0,65 \mathrm{mg} / \mathrm{kg}$ ve kaymakaltı sütünde $0,12 \mathrm{mg} / \mathrm{L}$ olarak tespit edildi. Aslam ve ark. (2011), keçi ve sığır sütlerinde $\mathrm{Ni}$ değerlerini sirasiyla $20,402 \mathrm{mg} / \mathrm{L}$ ve $22,394 \mathrm{mg} / \mathrm{L}$ düzeylerinde çok yüksek miktarlarda saptamışlardır. Bunun sebebinin endüstriyel kirlenmeye bağlı olarak topraktaki $\mathrm{Ni}$ miktarının artmasi ve kullanılan sulara bulaşması sonucu olabileceğini ileri sürmektedirler. Bu çalışmanın aksine yapılan birçok çalışmada Ni değerlerinin düşük olduğu görüldü. Kilıçel ve ark. (2003), Van'da üretilen otlu lorlarda Ni değerini $0,11 \mathrm{mg} / \mathrm{kg}$, Özlü ve ark. (2012), taze kaşarda $0,26 \mathrm{mg} / \mathrm{kg}$, olgunlaşmış kaşarda 0,30 $\mathrm{mg} / \mathrm{kg}$, Soylu ve Temiz (2011), sığır sütlerinde ortalama Ni 0,49 mg/kg olarak bulmuştur. Yalçın ve Tekinşen (2010) ise beyaz salamura, tulum ve kaşar peynirlerde her birinden 30'ar örnek olmak üzere toplamda 90 örnek üzerinde çalışmış ve $\mathrm{Ni}$ değerlerini sirasıyla $0,49 \mathrm{mg} / \mathrm{kg}, 0,65 \mathrm{mg} / \mathrm{kg}$ ve $0,43 \mathrm{mg} / \mathrm{kg}$ olarak bulmuşlardır. Bulduğumuz değerler bu araştırmacilarla benzer sonuçlar taşımaktadır. Türk Gıda Kodeksi, Gıda Maddelerinde Belirli Bulașanların Maksimum Seviyelerinin Belirlenmesi Hakkındaki Tebliğ'de (Türk Gıda Kodeksi, 2002) kaymak ve kaymak altı sütündeki Ni hakkında bir sınırlama bulunmamaktadir.

Yapılan çalışmada $\mathrm{Cu}$ değerleri incelendiğinde kaymakta $0,09 \mathrm{mg} / \mathrm{kg}$ olarak ve kaymak alt1 sütünde $0,02 \mathrm{mg} / \mathrm{L}$ olarak tespit edildi. Soylu ve Temiz (2011)'in yaptığı çalışmada $\mathrm{Cu}$ miktarı ortalama değerini $1,08 \mathrm{mg} / \mathrm{kg}$ olarak bulmuştur. Öksüztepe ve ark. (2013), çökelek ve kurut örneklerinde Cu miktarlarını çökelekte $1,13 \mathrm{mg} / \mathrm{kg}$ ve kurut örneklerinde $2,44 \mathrm{mg} / \mathrm{kg}$ olarak bulmuşlardır. Ankara'da yapılan bir çalışmada ise $\mathrm{Cu}$ miktarı sütte $4,30 \mathrm{mg} / \mathrm{kg}$ olarak saptanmıştır. $\mathrm{Cu}$ miktarındaki bölgesel farklılıkları sanayi ve otoyol yakınlığ1 ve bakııın mantarlara karşı kullanılmasından dolayı tarım ilaçlarından süte geçebileceğini şeklinde belirtmişlerdir (Temurci ve Güner, 2006). Yalçın ve Tekinşen (2010) Cu değerini beyaz salamura $1,44 \mathrm{mg} / \mathrm{kg}$, tulum peynirinde $1,06 \mathrm{mg} / \mathrm{kg}$, kaşar peynirinde 1,35 $\mathrm{mg} / \mathrm{kg}$ olarak bulmuşlardır. Bulunan bu değerlerin peynir yapımında kullanılan ekipmanlardan, tarım ilaçlarında kullanılan Cu'ın hayvanın yediği yemlerden kaynaklanabileceğini belirtmişlerdir.

Kaymakta Zn 8,27 mg/kg ve kaymakaltı sütünde $2,37 \mathrm{mg} / \mathrm{L}$ olarak tespit edildi. Kilıçel ve ark. (2003), otlu lorlardaki Zn ortalama değerini 29,9 $\mathrm{mg} / \mathrm{kg}$ bulmuşlardır. Yalçın ve Tekinşen (2010) beyaz salamura ve tulum ve kaşar peynirlerinde $\mathrm{Zn}$ değerlerini sırasıyla $15,35 \mathrm{mg} / \mathrm{kg}, 15,96 \mathrm{mg} / \mathrm{kg}$, $27,15 \mathrm{mg} / \mathrm{kg}$ olarak bulmuştur. Öksüztepe ve ark. (2013), Zn çökelekte 4,19 mg/kg ve kurut örneklerinde de 9,66 mg/kg bulmuşlardır. Soylu ve Temiz (2011) ise Tekke ilçesi köylerinden elde edilen süt örneklerinde ortalama çinko miktarını $13,33 \mathrm{mg} / \mathrm{kg}$ bulmuşlardır. Enb ve ark. 2009 manda ve inek sütleri toplayarak süt ürünleri elde edip yaptıkları ağır metal analizinde sütte $\mathrm{Zn}$ değerini $4,350 \mathrm{mg} / \mathrm{kg}$, yoğurtta $4,059 \mathrm{mg} / \mathrm{kg}$, kremada $19,570 \mathrm{mg} / \mathrm{kg}$ ve tereyağında 29,363 $\mathrm{mg} / \mathrm{kg}$ olarak tespit etmişlerdir. Bu çalışmalardaki $\mathrm{Zn}$ değerleri yapılan çalışma ile uyumludur. Şanlı (2002), endüstriyel bölge atmosferinde bulunan çinkonun oldukça yüksek olabileceğini ve element halinde bulunan çinkonun zehirli olmadığını bildirmiştir. Zn'nun otomotiv, azotlu gübreler, cam, çimento, metal, petrol, plastik - sentetik madde, termik enerji ve çelik endüstrisi vb. geniş bir kullanım alanı vardır (Küçükoğlu, 1996). Sütteki kontaminasyon sütün sağıldığı kaplardan kaynaklanabileceği gibi çevresel kontaminasyondan da kaynaklanabilir.

Kaymakta As değeri $0,14 \mathrm{mg} / \mathrm{kg}$ ve kaymakaltı sütünde $0,04 \quad \mathrm{mg} / \mathrm{L}$ olarak tespit edildi. İstanbulluoğlu ve ark. (2013), yaptıkları çalışmada açıkta satılan sütte As'i ortalama olarak $0,5 \mathrm{mg} / \mathrm{kg}$ olarak bulmuşlardır. Açıkta satılan sütlerdeki As miktarının yüksek oluşunu hijyen koşullarına uyulmamasının bir sonucu olabileceğini bildirmişlerdir. Ayar ve ark. (2007), Konya'da süt ve süt ürünlerinin ağır metal kontaminasyonu üzerine yaptıkları çalışmada As’i $0,146 \mathrm{mg} / \mathrm{kg}$ olarak en yüksek tereyağında bulmuşlardır. Aslam ve ark. (2011), keçi ve sığır sütlerinde As değerlerini sirasiyla $0.403 \mathrm{mg} / \mathrm{L}$ ve $0.078 \mathrm{mg} / \mathrm{L}$ düzeylerinde saptamışlar. Türk Gıda Kodeksi (2002), gidalarda As'in limitlerini $0,1-1 \mathrm{mg} / \mathrm{kg}$ olarak bildirmiştir. Araştırma sonucu incelendiğinde bulunan değerler bu sınırın içinde olduğu görülmektedir. As ile maruziyet volkanik patlamalar ve yeraltı suları gibi doğal nedenlerden olabileceği gibi ahşap koruma, pestisitler, yakıtların yakılması gibi antropojenik nedenlerden kaynaklanabilir (Güven ve ark., 2004).

Kaymakta Se $0,94 \mathrm{mg} / \mathrm{kg}$ ve kaymakaltı sütünde $0,17 \mathrm{mg} / \mathrm{L}$ olarak tespit edildi. İstabulluoğlu ve ark. (2012), çeşitli süt ve ürünlerinde yaptığı çalışmada Se değerini açıtkta satılan kaşarda $0,5 \mathrm{mg} / \mathrm{kg}$ olarak bulmuştur ve Selenyumun çevreye yayınımının olası yollardan birini de insan ve hayvanlarda gida takviyelerinin yoğun kullanımı olabileceğini söylemişlerdir. Ayar ve ark. (2007), çeşitli süt ve ürünlerinde bazı ağır metalleri incelemişler ve en yüksek Se değerini $0,434 \mathrm{mg} / \mathrm{kg}$ ile tulum peynirinde daha sonra en yüksek değeri 0,315 $\mathrm{mg} / \mathrm{kg}$ ile tereyağında tespit etmiştir.

Mo diğer metallerin aksine kaymakta tespit edilmedi fakat kaymakaltı sütünde tespit edildi. 
Kaymakaltı sütünde $0,04 \mathrm{mg} / \mathrm{L}$ olarak tespit edildi. Mo'in nispeten düşük toksisiteli olduğu ve bitkilere topraktan geçebileceği bildirilmiştir (İpek, 2003). Benincasa ve ark. (2008), manda sütünde Mo ortalama değerini $16,9 \mu \mathrm{g} / \mathrm{kg}$ ve inek sütünde 29,0 $\mu \mathrm{g} / \mathrm{kg}$ olarak bulmuşlardır. Mo'in kaymakta görülmemesi sadece kaymakaltı sütünde görülmesi kaymağın Mo bağlamadığını düşündürmüştür.

Ba kaymakta $0,17 \mathrm{mg} / \mathrm{kg}$ ve kaymakaltı sütünde $0,13 \mathrm{mg} / \mathrm{L}$ olarak tespit edildi. Ba kullanım alanı oldukça geniş bir metaldir ve bu nedenle doğada sık olarak bulunabilmekte bitkiler vasitasıyla hayvanlara geçebilmektedir. Yine ilaç kalıntılarıly $\mathrm{Ba}$ sütte kontaminasyona neden olabilmektedir (Belitz ve ark., 2009). Tip alanında kullanımı da çevreye yayınımının söz konusu olabileceğini düşündürmüştür (Şanl1, 2002). İstanbulluoğlu ve ark. (2012), yaptı̆̆ bir çalışmada sütte baryum içeriğini ambalajlı sütlerde $8,3 \mathrm{mg} / \mathrm{kg}$ olarak açıkta satilanlarda $1,7 \mathrm{mg} / \mathrm{kg}$ olarak bulmuştur. Benincasa ve ark. (2008), manda sütünde Ba miktarını 330 $\mu \mathrm{g} / \mathrm{kg}$ ve inek sütünde $226 \mu \mathrm{g} / \mathrm{kg}$ olarak tespit etmişlerdir. Bulduğumuz değerler belirtilen değerlerden daha düşük olduğu görüldü.

Toplam kaymaktaki ve kaymakaltı sütündeki $\mathrm{Pb}$ miktar1 $0,01 \mathrm{mg} / \mathrm{kg}$ ve $0,01 \mathrm{mg} / \mathrm{L}$ olarak tespit edildi. Soylu ve Temiz (2011) ortalama $\mathrm{Pb}$ değerini sütte $0,04 \mathrm{mg} / \mathrm{kg}$ olarak tespit etmişlerdir. Özlü ve ark. (2012) taze ve olgunlaşmış kaşar peynirlerde $\mathrm{Pb}$ miktarın s sirasiyla $1,60 \mathrm{mg} / \mathrm{kg}$ ve $2,25 \mathrm{mg} / \mathrm{kg}$ olarak tespit etmişlerdir. Buldukları bu değerin süt üretiminin yapıldığ1 çiftlikler, peynir işletmeleri ile satış yerlerinin sanayi kuruluşlarına ve otoyollarına olan mesafesiyle ilişkili olabileceğinin kanısına varmışlardır. Özçetin ve ark. (2013) anne sütünde ağır metal analizi üzerine yaptıkları çalışmada $\mathrm{Pb}$ ortalama değerini 26, $71 \mu \mathrm{g} / \mathrm{L}$ olarak tespit etmişlerdir. Ayar ve ark. (2007) süt ve ürünlerinde ağır metal analizinde $\mathrm{Pb}$ miktarını süte göre peynir, yoğurt çeşitleri ve tereyağinda daha yüksek bulmuşlardır. Sütte $0,10 \mathrm{mg} / \mathrm{kg}$, tereyağında 0,11 $\mathrm{mg} / \mathrm{kg}$, süzme yoğurtta $0,13 \mathrm{mg} / \mathrm{kg}$, kaşar peynirinde $1,10 \mathrm{mg} / \mathrm{kg}$ olarak tespit etmişlerdir. Peynirde Pb miktarının yüksek çıkmasını ise Pb'un kazein tarafindan bağlanması nedeniyle olabileceğini bildirmişlerdir. Yalçın ve Tekinşen (2010) yaptıkları çalışmada ortalama $\mathrm{Pb}$ seviyesini beyaz salamura peynirlerinde $0,13 \mathrm{mg} / \mathrm{kg}$, tulum peynirlerinde $0,08 \mathrm{mg} / \mathrm{kg}$ ve kaşar peynirlerinde $0,12 \mathrm{mg} / \mathrm{kg}$ olarak tespit etmişlerdir. Yapılan çalışmada tüm örneklerin $\mathrm{Pb}$ bakımından çok düşük değerlere sahip olması nedeniyle bu ağır metal yönünden sağlık açısından herhangi bir tehdit oluşturmayacağı kanaati oluşmaktadır.
Toplam kaymak ile kaymakaltı sütleri karşılaştırıldığında ise Ag hiçbir kaymakta ve kaymakaltı sütünde tespit edilmedi. Mo kaymakta tespit edilmemişken kaymak altı sütünde tespit edildi. Diğer tüm ağır metaller yönünden bakıldığında kaymakta kaymakaltı sütüne göre yüksek olduğu görülmektedir. Yapılan çalışmalarda bazı ağır metallerin enzimlerin sülfhidril gruplarına etki edebileceğini ve fosfolipidlerin yapısında bulunabileceğini göstermektedir. Örneğin $\mathrm{Cu}$ metali yağ globül membranındaki proteinlerde sütteki diğer proteinlere göre daha yüksek bakır içerdiği gözlenmiştir (Yüzbaşı ve Sezgin 2002). Ayar ve ark. (2007), tarafindan gerçekleştirilen süt ve süt ürünleri ağır metal düzeyleri üzerine yapılan bir çalışmada tereyağı ağır metal düzeyi diğer ürünlere oranla yüksek çıktığ1 görülmüştür. Çalışmamızdaki bulgular bu çalışmalarla uyumluluk göstermektedir. Enb ve ark. (2009) topladikları inek ve manda sütlerinin ve sütlerden elde ettikleri ürünlerin ağır metal düzeylerini incelemişlerdir. Metal düzeyleri incelendiğinde genel olarak süt ve yoğurda göre krema ve tereyağı gibi yağlı ürünlerin metal düzeylerinin daha yüksek olduğu görülmüştür.

Sonuç olarak; kaymak ve kaymakaltı sütleri ağır metal düzeyleri yönünden karşılaştırıldığında kaymak numunelerindeki ağır metal seviyelerinin daha yüksek olduğu görülmektedir. Ağır metal miktarlarına genel olarak bakıldığında Türk Gıda Kodeksi'nde verilen sinırlar içinde yer almaktadır. Ayrıca, bulunan değerler bakımından kaymak ve kaymakaltı sütü örneklerinin sağllk yönünden herhangi bir tehlike arz etmediği söylenebilir. Kaymakta Mn, Fe, Co, Zn, Se gibi esansiyel iz elementlerinin kaymakaltı süte göre daha yüksek bulunması kaymağın besleyici değerinin fazla olduğunu göstermiştir.

\section{KAYNAKÇA}

Adam RC. Süt III. Çeşitli Ürünler ve Artıkları. E.Ü.Z.F. Yayınlar1, İzmir. 1971; No: 170.

Akalın AS, Gönç S, Ünal G, Ökten S. Determination of Some Chemical and Microbiological Characteristics of Kaymak. Grasas Y Aceites. 2006; 57 (4): 429-432.

Aslam B, Javed I, Khan FH. "Uptake of heavy metal residues from sewerage sludge in the milk of goat and cattle during summer season." Pakistan Veterinary Journal. 2011; 31 (1): 75-77.

Ayar A, Sert D, Akın N. Konya'da Tüketime Sunulan Süt ve Süt Ürünlerinin Ağır Metal İçeriklerinin Belirlenmesi. Selçuk 
Üniversitesi, Ziraat Fakültesi Dergisi. 2007; 21 (41): $58-64$.

Belitz HD, Grosch W, Schieberle P. Milk and Dairy Products. Food Chemistry. 4thed. München: Springer. 2009; P. 523.

Benıncasa C, Levis J, Sindona G, Tagarellı A. The Use of Multi Element Profiling to Differantiate Between Cow and Buffalo Milk. Food Chemistry. 2008; 110: 257 - 262.

Çon AH, Gökçe R, Gürsoy O. Farklı Şekillerde Ambalajlanan Afyon Kaymaklarının Muhafaza Sürelerinin Belirlenmesi Üzerine Bir Araştırma. VI Süt ve Süt Ürünleri Sempozyumu,. Tekirdağ. S. 2000; $557-566$.

Enb A, Abou Donia MA, Abd-Rabou NS, Abou-Arab AAK, El-Senaity MH. Chemical Composition of Raw Milk and Heavy Metals Bahavior During Processing of Milk Products. Global Veterinaria. 2009; 3 (3): $268-275$.

Goyer RA. Toxic effects of metals. In: Caserett and Doull's Toxicology. The Basic Science of Poisons (Eds. Amdur M. O., Doull, J., Klaassen, C. D.) Pergamon Press, New York. 1991; 1032.

Güven A, Kahvecioğlu Ö, Kartal G, Timur S. Metallerin Cevresel Etkileri-III. TMMOB Metalurji Mühendisleri Odas1. Metalurji Dergisi. 2004; 138: 64-71.

İpek H. Molibden, YYÜ. Vet. Fak. Derg. 2003; 14(1): 73-76.

İstanbulluoğlu H, Oğur R, Tekbaş FÖ, Bakır B. Süt ve Süt Ürünlerinde Ağır Metal Kirliliği. Türkiye Klinikleri J. Med. Sci. 2013; 33 (2): $410-419$.

Kahvecioğlu Ö, Kartal G, Güven A, Timur S. Metallerin Çevresel Etkileri-I. Metalurji Dergisi. 2003; 136: 47 - 53.

Kılıçel F, Tarakçı Z, Sancak H, Durmaz H. Otlu Lorların Mineral Madde ve Ağır Metal İçerikleri. Yüzüncü Yıl Üniversitesi, Ziraat Fakültesi. Tarım Bilimleri Dergisi. 2004; 14(1): 41- 45.

Kurt A, Özdemir S. Erzurum'da Yapıllp Satılan Kaymakların Bileşimi ve Mikrobiyolojik Kalitesi. Gıda, 1988; 13: 205 - 208.

Küçükoğlu M. Zebra Balı̆̆ının (Brachydanio rerio) Embriyolojik Gelișimi Üzerine Kadmiyum Klorür ve Çinko Klorür gibi Çevre Kirleticilerinin Etkileri. Yüksek Lisans Tezi, Çukurova Üniversitesi. Adana. 1996.
Öksüztepe G, İncili KG, Uysal Aİ. Elazığ'da Satılan Çökelek ve Kurutların Mineral Madde ve Ağır Metal Düzeyleri. E - Jornal New World Science Academy. 2013; 8 (3): 1 -9 .

Özçetin M, Yılmaz R, Mendil D, Koçyiğit R, Çedik Kulak D. Presence of Toxic Heavy Metals in Human Breast Milk. Journal of Clinical and Analytical Medicine, 2013; 4 (2): $89-92$.

Özlü H, Atasever AM, Urçar S, Atasever M. Erzurum'da Tüketime Sunulan Kaşar Peynirlerinin Mineral Madde İçeriği ve Ağır Metal Kontaminasyonu. Kafkas Üniv. Vet. Fak. Derg., 2012; 18 (2): 205 - 208.

Soylu A, Temiz H. (2011). Samsun'da Sanayi Emisyonlarının Yöre Sığır Sütlerinin Ağır Metal İçeriğine Etkisi. Samsun Sempozyumu.

Şanlı Y. Veteriner Klinik Toksikoloji, Güngör Matbaacilik, Ankara. 2002.

Tekinşen C. "Süt Ürünleri Teknolojisi”, Selçuk Üniversitesi Basımevi, Konya. 2000.

Temurci H, Güner A. "Ankara'da Tüketime Sunulan Süt ve Beyaz Peynirlerde Ağır Metal Kontaminasyonu." Atatürk Üniversitesi Veteriner Bilimleri Dergisi. 2006; 1.2.

TGK, Türk G1da Kodeksi Gıda Maddelerinde Belirli Bulaşanların Maksimum Seviyelerinin Belirlenmesi Hakkında Tebliğ, T.C. Tarım ve Köyişleri Bakanlığı, Ankara, 2002. (Erişim Tarihi: 25.02.2015)

Yalçın Ö, Tekinşen KK. Konya'da Tüketime Sunulan Salamura, Tulum ve Kaşar Peynirlerinin Ağı Metal İçeriklerinin Araştırılması. Etlik Vet. Mikrobiyol. Derg. 2010; 21: 5 - 10 .

Yüzbaşı N, Sezgin E. Süt Ve Ürünlerindeki Metalik Kontaminantların Toksikolojik Etkileri, G1da. 2002; 27 (2): 121-127.

Zheljazkov VD, Nielsen NE. Effect of Heavy Metals on Peppermint and Commint. Plant and Soil. 1996; 178 (1): 59-66. 